\title{
FORMULASI STRATEGI PENGEMBANGAN DESTINASI PARIWISATA DENGAN MENGGUNAKAN METODE ANALISIS SWOT: STUDI KASUS KAWASAN PECINAN KAPASAN SURABAYA
}

\author{
Rizki Adityaji \\ Fakultas Pariwisata Universitas Ciputra \\ Surabaya
}

Korespodensi dengan Penulis:

Rizki Adityaji: Telp: 08123038 5727;

E-mail: radityaji@ciputra.ac.id

\begin{abstract}
The Chinatown area of Kapasan has considerable potential to become a tourist destination that can attract tourists to visit. But in fact, the number of tourist visits both domestic and foreign to the Chinatown area of Kapasan is still very low when compared with other tourist objects in Surabaya. For that needed a tourism development strategy to improve the quality of tourism destinations in the Chinatown area of Kapasan. This study aims to find the formulation of tourism development strategy of the Chinatown area of Kapasan by using SWOT analysis tool. The strengths, weaknesses, opportunities and threats posed by Kapasan as one of the oldest tourist destinations in Surabaya are comprehensively analyzed. From the analysis result, it is found that the Chinatown area of Kapasan is considered to have low competitive power to face the threat from other tourist destinations. Therefore a workable strategy is to adopt a defensive strategy that focuses on the most preferred markets. The steps that need to be taken include increasing information and promotion about the Chinatown area of Kapasan as heritage tourism area; utilizing the CSR funds offered by big companies; proposed the Chinatown area of Kapasan to be included in the agenda of annual tourism program of Surabaya city government for example on the anniversary of Surabaya city anniversary. In addition it is also necessary to improve the quality and quantity of infrastructure and supporting facilities.
\end{abstract}

Keywords: strategy; tourism development; SWOT analysis

\begin{abstract}
ABSTRAK
Kawasan pecinan Kapasan memiliki potensi yang cukup besar untuk menjadi sebuah destinasi wisata yang bisa menarik minat wisatawan untuk berkunjung. Namun pada kenyataannya, jumlah kunjungan wisatawan baik domestik maupun mancanegara ke kawasan pecinan Kapasan masih sangat rendah bila dibandingkan dengan obyek-obyek wisata lainnya di Surabaya. Untuk itu diperlukan strategi pengembangan pariwisata untuk meningkatkan kualitas destinasi pariwisata di kawasan pecinan Kapasan. Penelitian bertujuan untuk menemukan formulasi strategi pengembangan destinasi wisata kawasan pecinan Kapasan dengan menggunakan alat analisis SWOT. Kekuatan, kelemahan, peluang dan ancaman yang dimiliki oleh Kapasan sebagai salah satu destinasi wisata yang cukup lama di Surabaya dianalisis secara komprehensif. Dari hasil analisis tersebut diperoleh gambaran bahwa kawasan pecinan Kapasan dipandang memiliki daya kompetitif yang rendah untuk menghadapi ancaman dari destinasi wisata
\end{abstract}


lainnya. Oleh karena itu strategi yang yang bisa diterapkan adalah melakukan strategi defensif yang memfokuskan pada pasar yang paling disukai. Langkah-langkah yang perlu diambil diantaranya adalah lebih meningkatkan informasi dan promosi tentang kawasan pecinan Kapasan sebagai kawasan wisata heritage; memanfaatkan dana CSR yang ditawarkan oleh perusahaan-perusahaan besar; mengusulkan kawasan pecinan agar dimasukkan dalam agenda program wisata tahunan pemerintah kota Surabaya misalnya pada saat peringatan hari ulang tahun kota Surabaya. Selain itu diperlukan juga pembenahan kualitas dan kuantitas infrastruktur dan fasilitas penunjang.

Kata kunci: strategi; pengembangan pariwisata; analisis SWOT

\section{PENDAHULUAN}

Pemerintah Indonesia di bawah kepemimpinan Presiden Joko Widodo sangat intensif dalam melaksanakan pembangunan infrastruktur seperti pembangunan jalan tol baru, penambahan jalur kereta api, pembangunan bandara dan pelabuhan laut dan lain sebagainya. Pemerintah pusat menilai bahwa pembangunan infrastruktur di Indonesia masih tertinggal jauh dibandingkan negara lain (Sekretariat Kabinet RI, 2017). Pembangunan infrastruktur tersebut bertujuan untuk merespon perubahan yang terjadi di dunia industri secara keseluruhan. Salah satu sektor industri yang berubah tersebut adalah industri pariwisata. Industri pariwisata saat ini dipandang sebagai sektor yang sangat menguntungkan Indonesia karena banyaknya potensi wisata yang dapat dikembangkan lagi secara optimal (Cholik, 2017; Mariyono, 2017). Salah satunya adalah penerimaan pendapatan daerah di suatu wilayah yang memiliki destinasi wisata akan memiliki potensi untuk meningkat juga (Incera \& Fernández, 2015). Dengan demikian, perkembangan pariwisata di Indonesia tidak lepas dari pengembangan pariwisata di level daerah (Oktavio, 2017; Sutanto, 2016).

Di Surabaya, sektor pariwisata juga tidak luput dari perhatian pemerintah kota setempat. Selama ini, perencanaan pengembangan pariwisata kota Surabaya dituangkan dalam Rencana Pembangunan Jangka Menengah Daerah (RPJMD). Salah satu indikator yang digunakan oleh pemerintah kota Surabaya dalam menilai keberhasilan pengembangan sektor pariwisatanya adalah perbandingan jumlah kunjungan wisatawan berdasarkan obyek wisata dibandingkan dengan total kunjungan wisata ke Surabaya. Dalam RPJMD 2016-2021, diketahui bahwa pencapaian perbandingan jumlah kunjungan wisatawan berdasarkan obyek wisata dibandingkan dengan total kunjungan wisata ke Surabaya sepanjang tahun 2010-2015 masih relatif kecil. Hal ini mengindikasikan bahwa daya tarik obyek-obyek wisata yang ada di Surabaya secara keseluruhan belum dapat menarik minat wisatawan secara optimal sehingga masih diperlukan upaya pengembangan destinasi dan pemasaran pariwisata yang efektif dan menarik (Pemerintah Kota Surabaya, 2016). Dalam 
RPJMD juga disebutkan isu strategis prioritas pemerintah kota Surabaya yang salah satunya adalah melestarikan budaya lokal untuk mencegah pengaruh budaya yang negatif. Pemerintah kota Surabaya berpandangan bahwa dengan meningkatnya intensitas interaksi budaya di era global seperti sekarang ini maka dapat memunculikan ancaman bagi hilangnya kearifan budaya lokal kota. Pengukuran indeks budaya lokal merupakan cerminan dari kinerja beberapa variabel yang berkorelasi dengan kearifan lokal kota, seperti pelestarian budaya lokal. Salah satu destinasi wisata di Surabaya yang memiliki potensi wisata budaya namun belum dikelola dan dikembangkan secara optimal adalah kawasan pecinan. Potensi yang dimaksud adalah masih adanya warisan budaya Tionghoa yang dilestarikan, sifat terbuka dan keramahtamahan masyarakat setempat, serta living culture lainnya yang memiliki keterkaitan yang sangat erat dengan tradisi dan budaya warisan (Prasetya \& Wibisono, 2015). Sehingga, bila dikaitkan dengan isu strategis pemerintah kota Surabaya tersebut, maka nilai-nilai budaya dan sejarah yang dimiliki oleh kawasan pecinan patut untuk dilestarikan juga.

Salah satu kawasan pecinan yang cukup lama di Surabaya adalah kawasan pecinan Kapasan yang sudah menjadi pemukiman masyarakat Tionghoa sejak abad 19. Dinamakan Kapasan karena dulunya kawasan ini banyak ditumbuhi pohon randu atau pohon kapas, sehingga diberi nama Kapasan. Kawasan pecinan Kapasan hingga kini masih lekat dengan budaya Tionghoa baik yang berbentuk fisik maupun non-fisik seperti kelenteng Boen Bio yang didirikan pada tahun 1883 (Fitrianto, 2013) sehingga kawasan Kapasan juga disebut Kapasan Boen Bio atau yang saat ini lebih dikenal dengan nama Kapasan Dalam (Kartono, 2012). Pemukiman warga Tionghoa di kawasan pecinan Kapasan berbentuk kapling-kapling kecil dan masih terdapat beberapa rumah yang memiliki desain arsitektur khas Tionghoa (Gambar 1).

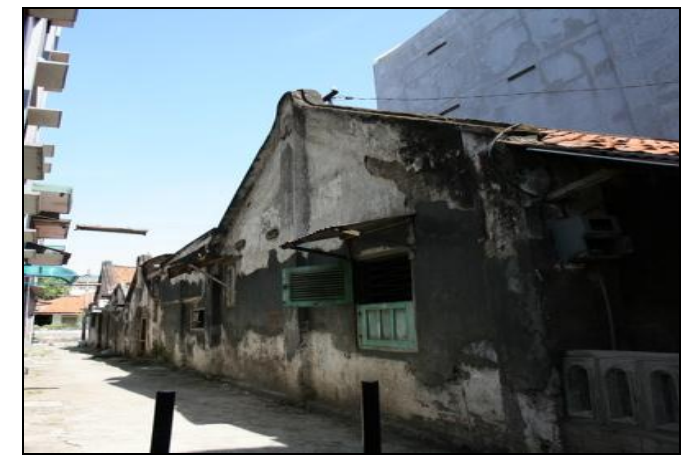

Gambar 1. Rumah Tionghoa di Kapasan Sumber: Observasi lapangan (2018) 
Aktivitas kekerabatan warga Tionghoa di kawasan pecinan Kapasan yang hingga kini masih berjalan salah satunya adalah arena berlatih kungfu. Selain itu juga ada acara kebudayaan tahunan yang disebut Sedekah Bumi untuk memperingati hari kelahiran nabi Konghucu. Acara Sedekah Bumi menampilkan pertunjukan wayang dan tarian barongsai yang melibatkan warga setempat.

Melihat gambaran potensi yang dimiliki Kapasan, maka seharusnya Kapasan mampu menjadi sebuah destinasi wisata yang bisa menarik minat wisatawan untuk berkunjung. Namun pada kenyataannya jumlah kunjungan wisatawan baik domestik maupun mancanegara ke kawasan pecinan Kapasan masih kalah dibandingkan dengan obyek-obyek wisata lainnya di Surabaya. Wisatawan cenderung berkunjung ke tempat wisata yang bernuansa modern seperti mal atau pusat hiburan lainnya (Arifah, 2015). Menurut Bapak Widodo Suryantoro, Kepala Dinas Kebudayaan dan Pariwisata Kota Surabaya, ada banyak destinasi wisata yang menjadi jujukan utama para wisatawan domestik maupun mancanegara saat berkunjung di Surabaya yaitu wisata belanja seperti mall dan sentra sentra UKM, lalu wisata kuliner dan ketiga wisata taman, dan keempat wisata alam (surya.co.id, 2017).

Berdasarkan kondisi di atas, maka Kapasan harus memiliki strategi untuk mengembangkan kualitas destinasi pariwisata di daerah tersebut. Oleh karena itu, penelitian ini ditulis dengan tujuan untuk memberikan perumusan strategi pengembangan pariwisata di kawasan pecinan Kapasan Surabaya dengan menggunakan analisis SWOT.

\section{METODE}

Penelitian ini merupakan penelitian deskriptif dengan pendekatan mixed method (kuantitatif dan kualitatif). Jenis data penelitian adalah data primer dan instrumen yang digunakan untuk pengumpulan data adalah kuesioner, survei lapangan dan wawancara yang dilakukan selama tiga bulan mulai bulan September sampai Nopember 2017.

Dalam industri pariwisata, jumlah populasi wisatawan sifatnya fluktuatif. Jumlah kunjungan wisatawan dapat dipengaruhi oleh faktor-faktor yang tidak terkendali, seperti kondisi ekonomi dan bencana alam (Louangrath \& Rewtrakunphaiboon, 2013). Oleh karena itu, jumlah populasi dalam penelitian di bidang pariwisata seringkali tidak dapat diketahui secara pasti (infinite population). Louangrath (2014) memberikan dua metode baru dalam perhitungan ukuran sampel untuk jumlah populasi yang tidak diketahui secara pasti. Salah

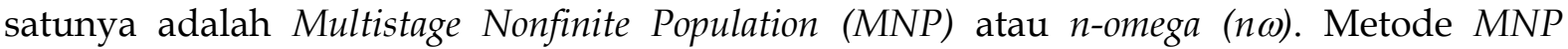
tersebut diperkenalkan pada tahun 2014 yang merupakan kontribusi terbaru untuk bidang 
metodologi penelitian dalam ilmu sosial. Kedua metode tersebut memberikan cara yang efisien untuk penentuan ukuran sampel minimum yang mana ukuran sampel minimum adalah 30 ( $\mathrm{n} \geq 30$ ). Louangrath (2014) berasumsi bahwa penggunaan persamaan standard error untuk penentuan ukuran sampel minimum merupakan sebuah kesalahan. Berdasarkan teori Louangrath (2014) tersebut, maka jumlah sampel dalam penelitian ini ditetapkan sebanyak 35 sampel.

Teknik penentuan sampel penelitian adalah purposive sampling yang termasuk dalam non-probability sampling dimana responden yang dijadikan sampel penelitian adalah wisatawan, baik domestik maupun mancanegara, yang pernah melakukan perjalanan wisata ke kawasan pecinan Kapasan.

Penelitian ini menggunakan analisis SWOT sebagai metode analisa data. Analisis SWOT merupakan salah satu metode perencanaan strategis yang sangat kompleks untuk menggambarkan situasi dan mengevaluasi sebuah permasalahan berdasarkan faktor internal dan eksternal, yaitu Strength (Kekuatan), Weakness (Kelemahan), Opportunity (Peluang), dan Threat (Ancaman). Variabel beserta indikator yang digunakan dalam penelitian ini merupakan elemen-elemen yang terkait dengan faktor internal dan eksternal dari destinasi wisata yang diadopsi dari penelitian Butowski (2010) seperti yang nampak dalam Tabel 1.

Tabel 1. Faktor Internal dan Eksternal Destinasi Wisata

\begin{tabular}{ll}
\hline Aset pariwisata (atraksi) & $\begin{array}{l}\text { Atraksi budaya (buatan manusia); historis dan } \\
\text { kontemporer; atraksi alam }\end{array}$ \\
\hline Fasilitas & $\begin{array}{l}\text { Akomodasi; kuliner; layanan dan fasilitas penunjang } \\
\text { lainnya }\end{array}$ \\
\hline $\begin{array}{l}\text { Promosi pariwisata dan } \\
\text { informasi }\end{array}$ & $\begin{array}{l}\text { Tanggung jawab pemerintah yang didukung oleh } \\
\text { partisipasi sektor swasta }\end{array}$ \\
\hline $\begin{array}{l}\text { Penciptaan dan } \\
\text { komersialisasi produk } \\
\text { pariwisata }\end{array}$ & $\begin{array}{l}\text { Tanggung jawab sektor swasta yang didukung oleh } \\
\text { partisipasi pemerintah }\end{array}$ \\
\hline $\begin{array}{l}\text { Transportasi dan } \\
\text { infratruktur }\end{array}$ & Jaminan aksesibilitas transportasi eksternal dan internal \\
\hline $\begin{array}{l}\text { Sikap masyarakat lokal } \\
\text { terhadap wisatawan }\end{array}$ & $\begin{array}{l}\text { Keramahan; keterbukaan kepada tamu; pengetahuan; } \\
\text { bahasa asing; kewirausahaan (entrepreneurship) }\end{array}$ \\
\hline Dukungan pemerintah & $\begin{array}{l}\text { Kebijakan ekonomi (dorongan untuk investasi pariwisata); } \\
\text { jaminan keamanan; perlindungan kawasan heritage }\end{array}$ \\
\end{tabular}

Sumber: Butowski (2010) 
Komponen lain dari analisis data adalah Internal Factors Analysis Summary (IFAS) dan External Factors Analysis Summary (EFAS). IFAS terdiri dari kekuatan dan kelemahan sementara EFAS terdiri dari peluang dan ancaman. IFAS-EFAS ditentukan dengan mengevaluasi semua aspek SWOT (faktor internal dan eksternal) yang terkait dengan ketujuh variabel dalam Tabel 1 dan memberikan skor antara 0.00 dan 1.00 . Hasil total skor masing-masing faktor adalah 1. Langkah selanjutnya adalah mengalikan skor semua faktor dengan kriteria (rating) yang telah dirancang sebelumnya. Kriteria (rating) dalam analisis IFAS-EFAS untuk sektor pariwisata di kawasan pecinan Kapasan ditentukan berdasarkan asumsi sebagai berikut: a) kriteria 1 diberi rating 1 (rendah), b) kriteria 2 diberi rating 2 (cukup), dan c) kriteria 3 diberi rating 3 (tinggi). Hasil total dari perkalian skor dan kriteria (rating) akan menentukan nilai faktor X (kekuatan-kelemahan) dan faktor $\mathrm{Y}$ (peluangancaman) yang kemudian hasilnya dimasukkan ke dalam kuadran IFAS-EFAS untuk menggambarkan arah strategi yang harus dibuat.

\section{HASIL DAN PEMBAHASAN}

\section{Analisis SWOT}

Berdasarkan hasil penyebaran kuesioener dan wawancara, maka pemetaan kekuatan, kelemahan, peluang dan ancaman untuk analisis SWOT kawasan pecinan Kapasan dapat dilihat pada Tabel 2. Pemetaan tersebut pada hakikatnya merupakan proses pendataan dan pengidentifikasian sebagai pra analisis (Brata, Sunaryo, \& Yudaningtyas, 2015).

Tabel 2. Analisis SWOT Kawasan Pecinan Kapasan

\begin{tabular}{|c|c|c|c|}
\hline \multicolumn{2}{|c|}{ FAKTOR INTERNAL } & \multicolumn{2}{|c|}{ FAKTOR EKSTERNAL } \\
\hline $\begin{array}{c}\text { Strength } \\
\text { (Kekuatan) }\end{array}$ & $\begin{array}{c}\text { Weakness } \\
\text { (Kelemahan) }\end{array}$ & $\begin{array}{l}\text { Opportunity } \\
\text { (Peluang) }\end{array}$ & $\begin{array}{c}\text { Threat } \\
\text { (Ancaman) }\end{array}$ \\
\hline $\begin{array}{l}\text { Destinasi wisata } \\
\text { yang } \\
\text { mengandalkan } \\
\text { kekuatan sejarah } \\
\text { dan budaya } \\
\text { - Klenteng } \\
\text { legendaris Boen } \\
\text { Bio sebagai } \\
\text { landmark Kapasan } \\
\text { - Masyarakat lokal } \\
\text { sangat ramah } \\
\text { Kawasan } \\
\text { perdagangan }\end{array}$ & $\begin{array}{l}\text { - Sarana } \\
\text { transportasi } \\
\text { umum menuju } \\
\text { kawasan pecinan } \\
\text { Kapasan kurang } \\
\text { menunjang } \\
\text { - Kurangnya } \\
\text { partisipasi anak } \\
\text { muda dalam } \\
\text { pelestarian } \\
\text { budaya } \\
\text { - Lampu } \\
\text { penerangan }\end{array}$ & $\begin{array}{l}\text { - Cukup banyak } \\
\text { hotel baru yang } \\
\text { berdiri di sekitar } \\
\text { kawasan pecinan } \\
\text { Kapasan } \\
\text { - Cukup banyak } \\
\text { pusat } \\
\text { perbelanjaan di } \\
\text { sekitar kawasan } \\
\text { pecinan Kapasan } \\
\text { - Banyak } \\
\text { wisatawan yang } \\
\text { berminat dengan }\end{array}$ & $\begin{array}{l}\text { - } \begin{array}{l}\text { Kurangnya } \\
\text { dukungan }\end{array} \\
\text { pemerintah } \\
\text { - Pengembangan } \\
\text { wisata di } \\
\text { kawasan } \\
\text { pecinan } \\
\text { Kapasan tidak } \\
\text { menarik minat } \\
\text { investor } \\
\text { - Rendahnya } \\
\text { konsistensi } \\
\text { terhadap }\end{array}$ \\
\hline
\end{tabular}




\begin{tabular}{|c|c|c|c|}
\hline $\begin{array}{l}\text { terbesar di } \\
\text { Surabaya dan } \\
\text { Indonesia Timur } \\
\text { sejak era kolonial }\end{array}$ & $\begin{array}{l}\text { sangat minim } \\
\text { terutama malam } \\
\text { hari } \\
\text { - } \text { Tidak tersedia } \\
\text { agenda program } \\
\text { wisata yang jelas } \\
\text { - Kurangnya pusat } \\
\text { informasi dan } \\
\text { sarana promosi } \\
\text { - Tidak ada tempat } \\
\text { penjualan } \\
\text { souvenir } \\
\text { - Migrasi } \\
\text { penduduk lokal } \\
\text { Kapasan ke } \\
\text { kawasan lain }\end{array}$ & $\begin{array}{l}\text { wisata sejarah } \\
\text { dan budaya } \\
\text { - Revitalisasi } \\
\text { kawasan sungai } \\
\text { Kalimas oleh } \\
\text { pemerintah kota } \\
\text { - Dekat pusat } \\
\text { kuliner }\end{array}$ & $\begin{array}{l}\text { pelestarian } \\
\text { cagar budaya } \\
\text { oleh } \\
\text { masyarakat } \\
\text { umum } \\
\text { - Banyaknya } \\
\text { atraksi wisata } \\
\text { lainnya di kota } \\
\text { Surabaya yang } \\
\text { lebih menarik }\end{array}$ \\
\hline
\end{tabular}

\section{Analisis IFAS-EFAS}

Analisis IFAS-EFAS merupakan analisis terhadap berbagai macam faktor strategis pada lingkungan internal dan eksternal dengan cara memberikan bobot dan rating pada setiap faktor strategis tersebut. Faktor-faktor strategis adalah faktor-faktor dominan dari kekuatan, kelemahan, peluang dan ancaman yang memberikan dampak terhadap situasi dan kondisi yang ada serta memberikan manfaat bila dilakukan tindakan positif (Dyson, 2004). Menganalisis lingkungan internal dan eksternal berguna untuk memonitor masalahmasalah yang dapat mempengaruhi pariwisata dimasa yang akan datang (Goranczewski \& Puciato, 2010; Lawton \& Weaver, 2009).

Berdasarkan analisis IFAS seperti yang disajikan pada Tabel 3, diketahui bahwa total skor untuk kekuatan dan kelemahan adalah 1,117 dan 1,693, sehingga total skor kelemahan lebih besar dibandingkan total skor kekuatan. Oleh karena itu, langkah pertama yang bisa dilakukan dalam program pengembangan pariwisata di kawasan pecinan Kapasan adalah mengidentifikasi permasalahan din internal serta mencari solusinya agar dapat meminimalisir kelemahan. Faktor-faktor yang menjadi kelemahan tersebut memiliki pengaruh yang cukup signifikan untuk menghambat pengembangan pariwisata di kawasan pecinan Kapasan. 
Tabel 3. Internal Factors Analysis Summary (IFAS)

\begin{tabular}{|c|c|c|c|c|c|c|c|}
\hline Strength & $\begin{array}{c}\text { Score } \\
\text { (b) }\end{array}$ & $\begin{array}{c}\text { Rate } \\
\text { (r) }\end{array}$ & $\mathbf{b} \times \mathbf{r}$ & Weakness & $\begin{array}{c}\text { Score } \\
\text { (b) }\end{array}$ & $\begin{array}{c}\text { Rate } \\
\text { (r) }\end{array}$ & $\mathbf{b} \times \mathbf{r}$ \\
\hline $\begin{array}{l}\text { Destinasi wisata yang } \\
\text { mengandalkan kekuatan } \\
\text { sejarah dan budaya }\end{array}$ & 0.116 & 3 & 0.348 & $\begin{array}{l}\text { Sarana transportasi umum } \\
\text { menuju kawasan pecinan } \\
\text { Kapasan kurang } \\
\text { menunjang }\end{array}$ & 0.107 & 3 & 0.321 \\
\hline $\begin{array}{l}\text { Klenteng legendaris Boen } \\
\text { Bio sebagai landmark } \\
\text { Kapasan }\end{array}$ & 0.107 & 3 & 0.321 & $\begin{array}{l}\text { Kurangnya partisipasi anak } \\
\text { muda dalam pelestarian } \\
\text { budaya }\end{array}$ & 0.056 & 2 & 0.112 \\
\hline $\begin{array}{l}\text { Masyarakat lokal sangat } \\
\text { ramah }\end{array}$ & 0.071 & 2 & 0.142 & $\begin{array}{l}\text { Lampu penerangan sangat } \\
\text { minim terutama malam } \\
\text { hari }\end{array}$ & 0.098 & 3 & 0.294 \\
\hline \multirow[t]{4}{*}{$\begin{array}{l}\text { Kawasan perdagangan } \\
\text { terbesar di Surabaya dan } \\
\text { Indonesia Timur sejak era } \\
\text { kolonial }\end{array}$} & 0.102 & 3 & 0.306 & $\begin{array}{l}\text { Tidak tersedia agenda } \\
\text { program wisata yang jelas }\end{array}$ & 0.099 & 3 & 0.297 \\
\hline & & & & $\begin{array}{l}\text { Kurangnya pusat informasi } \\
\text { dan sarana promosi }\end{array}$ & 0.102 & 3 & 0.306 \\
\hline & & & & $\begin{array}{l}\text { Tidak ada tempat } \\
\text { penjualan souvenir }\end{array}$ & 0.079 & 3 & 0.237 \\
\hline & & & & $\begin{array}{l}\text { Migrasi penduduk lokal } \\
\text { Kapasan ke kawasan lain }\end{array}$ & 0.063 & 2 & 0.126 \\
\hline TOTAL & 0.396 & 11 & 1.117 & TOTAL & 0.604 & 19 & 1.693 \\
\hline
\end{tabular}

Analisis EFAS pada Tabel 4 menunjukkan bahwa bahwa total skor untuk peluang dan ancaman adalah 0,866 dan 1,094, sehingga total skor peluang lebih kecil dibandingkan total skor ancaman. Hal ini menandakan bahwa ancaman memiliki pengaruh yang lebih signifikan terhadap strategi pengembangan pariwisata kawasan pecinan Kapasan. Oleh karena itu, ancaman tersebut harus diminimalisir dan dicarikan solusi yang tepat sehingga ancaman tersebut semakin lama bukan lagi menjadi sesuatu hal yang serius.

Tabel 4. External Factors Analysis Summary (EFAS)

\begin{tabular}{|c|c|c|c|c|c|c|c|}
\hline Opportunity & $\begin{array}{c}\text { Score } \\
\text { (b) }\end{array}$ & $\begin{array}{c}\text { Rate } \\
\text { (r) }\end{array}$ & $\mathbf{b} \times \mathbf{r}$ & Threat & $\begin{array}{c}\text { Score } \\
\text { (b) }\end{array}$ & $\begin{array}{c}\text { Rate } \\
\text { (r) }\end{array}$ & $\mathbf{b} \mathbf{X r}$ \\
\hline $\begin{array}{l}\text { Cukup banyak hotel baru } \\
\text { yang berdiri di sekitar } \\
\text { kawasan pecinan Kapasan }\end{array}$ & 0.128 & 1 & 0.128 & $\begin{array}{l}\text { Kurangnya dukungan } \\
\text { pemerintah }\end{array}$ & 0.088 & 2 & 0.176 \\
\hline $\begin{array}{l}\text { Cukup banyak pusat } \\
\text { perbelanjaan di sekitar } \\
\text { kawasan pecinan Kapasan }\end{array}$ & 0.141 & 2 & 0.282 & $\begin{array}{l}\text { Pengembangan wisata di } \\
\text { kawasan pecinan Kapasaan } \\
\text { tidak menarik minat } \\
\text { investor }\end{array}$ & 0.087 & 3 & 0.261 \\
\hline $\begin{array}{l}\text { Banyak wisatawan yang } \\
\text { berminat dengan wisata } \\
\text { sejarah dan budaya }\end{array}$ & 0.119 & 2 & 0.238 & $\begin{array}{l}\text { Rendahnya konsistensi } \\
\text { terhadap pelestarian cagar } \\
\text { budaya oleh masyarakat } \\
\text { umum }\end{array}$ & 0.066 & 3 & 0.198 \\
\hline
\end{tabular}




\begin{tabular}{|c|c|c|c|c|c|c|c|}
\hline $\begin{array}{l}\text { Revitalisasi kawasan sungai } \\
\text { Kalimas oleh pemerintah } \\
\text { kota Surabaya }\end{array}$ & 0.097 & 1 & 0.097 & $\begin{array}{l}\text { Banyaknya atraksi wisata } \\
\text { lainnya di kota Surabaya } \\
\text { yang lebih menarik }\end{array}$ & 0.153 & 3 & 0.459 \\
\hline Dekat pusat kuliner & 0.121 & 1 & 0.121 & & & & \\
\hline TOTAL & 0.606 & 6 & 0.866 & TOTAL & 0.394 & 11 & 1.094 \\
\hline
\end{tabular}

Mengacu pada hasil hasil analisis IFAS-EFAS, maka selanjutnya dibuat kuadran IFAS-EFAS seperti yang nampak pada Gambar 2. Masing-masing kuadran memiliki rumusan strategi sebagai strategi utamanya. Untuk menentukan posisi pengembangan pariwisata kawasan pecinan Kapasan dalam kuadran IFAS-EFAS, maka harus dihitung terlebih dahulu nilai faktor $\mathrm{X}$ dan $\mathrm{Y}$. Nilai faktor $\mathrm{X}$ merupakan nilai faktor strategi internal yang membentuk garis horizontal dan didapatkan dari hasil pengurangan dari total skor kekuatan dan total skor kelemahan, sedangkan nilai faktor Y merupakan nilai faktor strategi eksternal yang membentuk garis vertikal dan didapatkan dari hasil pengurangan total skor peluang dan total skor ancaman (Azizah, 2017) seperti dalam persamaan berikut ini:

$$
\begin{aligned}
X & =\text { Kekuatan }- \text { Kelemahan } \\
& =1,117-1,693 \\
& =-0,576 \\
Y & =\text { Peluang }- \text { Ancaman } \\
& =0,866-1,094 \\
& =-0,228
\end{aligned}
$$

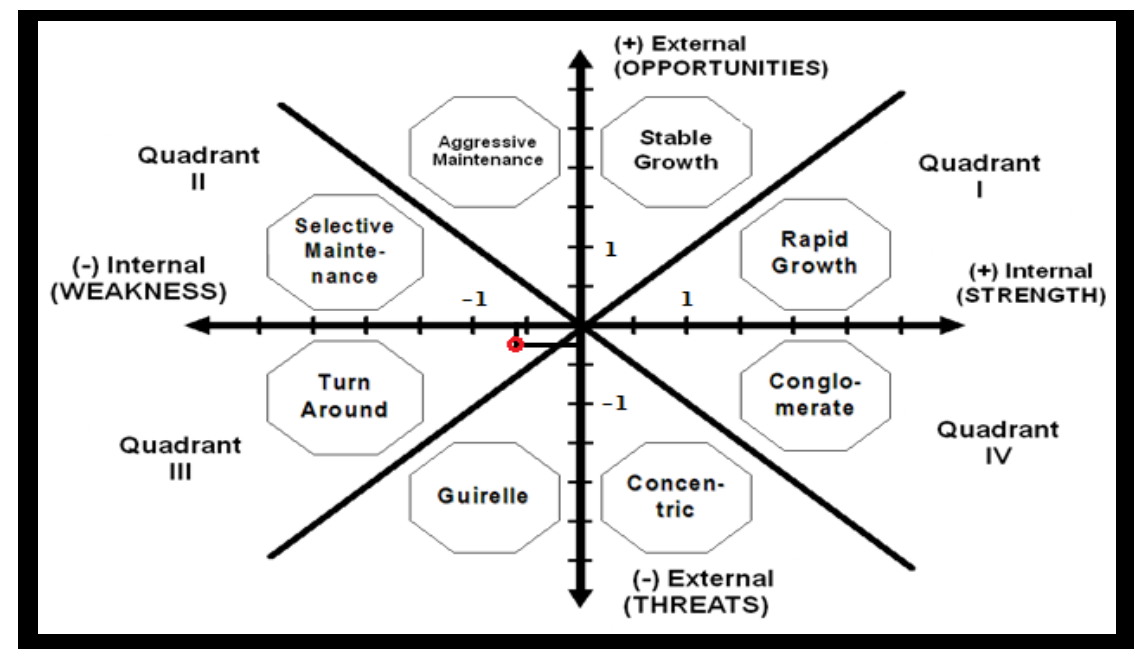

Sumber: Data diolah (2018)

Gambar 2. Kuadran IFAS-EFAS 


\section{Turn Around Strategy}

Berdasarkan kuadran IFAS-EFAS, maka pengembangan pariwisata kawasan pecinan Surabaya berada pada kuadran III khususnya pada area Turn Around Strategy. Kuadran ini menggambarkan situasi yang sangat tidak menguntungkan dimana harus menghadapi berbagai kelemahan internal dan ancaman eksternal (Tranggono, Dwiridhotjahjono, Aryani, \& Rasyidah, 2015). Kawasan pecinan Kapasan dipandang memiliki daya kompetitif yang rendah untuk menghadapi ancaman dari destinasi wisata lainnya. Oleh karena itu, strategi yang perlu dibangun adalah membalikkan berbagai macam kecenderungan negatif yang sedang terjadi sekarang ini, yang paling umum tertuju pada upaya pengelolaan yang lebih optimal (Chang \& Huang, 2006). Salah satu strategi yang yang bisa diadopsi untuk menghindari ancaman adalah melakukan strategi defensif yang memfokuskan pada pasar yang paling disukai. Akan tetapi, bila strategi defensif gagal, maka divestasi atau likuidasi bisa dijadikan opsi strategi selanjutnya.

Langkah lainnya yang bisa dilakukan menyikapi hasil kuadran IFAS-EFAS adalah mengembangkan alternatif-alternatif strategi yang dirumuskan dari hasil pemetaan sebelumnya terhadap masing-masing aspek SWOT dengan cara menggabungkan masingmasing aspek SWOT (Goranczewski \& Puciato, 2010) sebagai berikut:

a. Strategi yang menghubungkan Strength dan Opportunity (SO), yaitu mengeksplorasi warisan sejarah dan budaya dan mewujudkannya dalam bentuk atraksi wisata yang unik dan berbeda dengan atraksi wisata yang sudah ada; menggalakkan promosi; dan menjalin kerja sama yang lebih intensif dengan para pelaku bisnis pariwisata lainnya (hotel, mal, pusat kuliner)

b. Strategi yang menghubungkan Strength dan Threat (ST), yaitu melakukan eksplorasi lebih lanjut terhadap destinasi wisata sehingga memiliki keunggulan kompetitif dan mampu menarik minat investor; menggaungkan pentingnya pelestarian cagar budaya sebagai warisan generasi penerus; menjalin komunikasi yang lebih intensif dengan pemerintah selaku stakeholder utama bidang pariwisata agar dapat membuat sebuah kebijakan yang dapat membangkitkan dan mendorong wisatawan untuk berkunjung ke kawasan pecinan Kapasan.

c. Strategi yang menghubungkan Weakness dan Opportunity (WO), yaitu meningkatkan kualitas dan kuantitas infrastruktur dan fasilitas penunjang seperti mendirikan pusat souvenir; membuka pusat informasi wisata; mengagendakan program wisata tahunan; dan menggalakkan partisipasi masyarakat lokal khususnya anak muda melalui wadah karang taruna. 
d. Strategi yang menghubungkan Weakness dan Threat (WT), yaitu meningkatkan informasi dan promosi tentang kawasan pecinan Kapasan; memanfaatkan dana CSR yang ditawarkan oleh perusahaan-perusahaan besar untuk pengembangan wisata sejarah dan budaya kawasan pecinan Kapasan; mengusulkan kawasan pecinan agar dimasukkan dalam agenda program wisata pemerintah kota Surabaya misalnya pada saat peringatan hari ulang tahun kota Surabaya.

\section{Pemilihan Strategi}

Dari berbagai macam analisis formulasi strategi yang sudah dilakukan penulis di atas, maka pada akhirnya perlu dipilih sebuah strategi yang dapat meningkatkan peluang terbesar bagi kawasan pecinan Kapasan dalam upaya mengembangkan potensi wisatanya agar dapat memiliki daya saing yang tinggi. Formulasi strategi pada umumnya disebut juga sebagai perencanaan strategis yang merupakan proses penyusunan perencanaan jangka panjang, oleh karena itu prosesnya lebih banyak menggunakan proses analitis (Priyadi, 2000). Pemilihan strategi tersebut juga perlu mempertimbangkan beberapa faktor seperti tanggap dengan lingkungan eksternal (Arif \& Hossin, 2016), melibatkan keunggulan kompetitif (Lusticky \& Kincl, 2012), dan sejalan dengan strategi stakeholder lainnya (Formica \& Kothari, 2008). Oleh karena itu, para stakeholder yang berkepentingan dengan pengembangan pariwisata di kawasan pecinan Kapasan perlu duduk bersama dengan tujuan untuk membahas lebih lanjut strategi yang bisa diterapkan berdasarkan analisis formulasi strategi yang dibuat oleh penulis.

\section{KESIMPULAN}

Penelitian ini bertujuan untuk membuat formulasi strategi pengembangan destinasi wisata kawasan pecinan Kapasan dengan menggunakan alat bantu analisis yaitu SWOT. Kekuatan, kelemahan, peluang dan ancaman yang dimiliki oleh Kapasan sebagai salah satu destinasi wisata yang cukup lama di Surabaya dianalisis secara komprehensif. Dari hasil analisis tersebut diperoleh gambaran bahwa kawasan pecinan Kapasan dipandang memiliki daya kompetitif yang rendah untuk menghadapi ancaman dari destinasi wisata lainnya. Oleh karena itu strategi yang yang bisa diterapkan adalah melakukan strategi defensif yang memfokuskan pada pasar yang paling disukai. Langkah-langkah yang perlu diambil diantaranya adalah lebih meningkatkan informasi dan promosi tentang kawasan pecinan Kapasan sebagai kawasan wisata heritage; memanfaatkan dana CSR yang ditawarkan oleh perusahaan-perusahaan besar; mengusulkan kawasan pecinan agar dimasukkan dalam 
agenda program wisata tahunan pemerintah kota Surabaya misalnya pada saat peringatan hari ulang tahun kota Surabaya. Selain itu diperlukan juga pembenahan kualitas dan kuantitas infrastruktur dan fasilitas penunjang.

Keberadaan para stakeholder yang berkecimpung di industri pariwisata kota Surabaya tidak ada salahnya untuk menjalankan strategi yang direkomendasikan oleh penulis dan dilakukan evaluasi lebih lanjut. Sehingga, apabila masih terdapat kekurangan atau kelemahannya, hal tersebut bisa menjadi bahan kajian yang menarik dalam penelitianpenelitian selanjutnya.

\section{DAFTAR RUJUKAN}

Arif, T. M. H., \& Hossin, M. Z. (2016). A comparative analysis of internal and external environments between Hotel Hyatt, UK and Hotel The Cox Today, Cox's Bazar, Bangladesh. IOSR Journal of Humanities and Social Science, 21(6), 13-22. https://doi.org/10.9790/0837-2106031322

Arifah, I. N. (2015). Promotion strategy dan peran Dinas Kebudayaan dan Pariwisata dalam meningkatkan kunjungan wisatawan. Jurnal Ilmu $\mathcal{E}$ Riset Manajemen, 3(6), 1-18. Retrieved from https:/ / ejournal.stiesia.ac.id/jirm/article/view/543/514

Azizah, A. (2017). Tourism development and strategy for increasing numbers of visitors in Kediri. Journal of Indonesian Tourism and Development Studies, 5(2), 131-136. https://doi.org/10.21776/ub.jitode.2017.005.02.09

Brata, D. W., Sunaryo, \& Yudaningtyas, E. (2015). Fight for the spirit game bergenre RPG menggunakan Fuzzy-SWOT berbasis web. Jurnal EECCIS, 9(1), 55-62.

Butowski, L. (2010). Tourism as a development factor in the light of regional development theories. Tourism, 20(1), 5-10. https://doi.org/10.2478/v10106-010-0001-1

Chang, H. H., \& Huang, W. C. (2006). Application of a quantification SWOT analytical method. Mathematical and Computer Modelling, 43(1-2), 158-169.

https://doi.org/10.1016/j.mcm.2005.08.016

Cholik, M. A. (2017). The development of tourism industry in Indonesia: Current problems and challenges. European Journal of Research and Reflection in Management Sciences, 5(1), 49-59.

Dyson, R. G. (2004). Strategic development and SWOT analysis at the University of Warwick. European Journal of Operational Research, 152(3), 631-640. https://doi.org/10.1016/S0377-2217(03)00062-6

Fitrianto, H. A. (2013, July 15). Mengenang Gus Dur di Kelenteng Boen Bio. Kompasiana. Surabaya. Retrieved from https://www.kompasiana.com/jelajah_nesia/mengenanggus-dur-di-kelenteng-boen-bio_55287b50f17e61d4548b45a5

Formica, S., \& Kothari, T. H. (2008). Strategic destination planning: Analyzing the future of tourism. Journal of Travel Research, 46(4), 355-367. https://doi.org/10.1177/0047287507312410

Goranczewski, B., \& Puciato, D. (2010). SWOT analysis in the formulation of tourism development strategies for destinations. Tourism, 20(2), 45-53. 
https://doi.org/10.2478/v10106-010-0008-7

Incera, A. C., \& Fernández, M. F. (2015). Tourism and income distribution: Evidence from a developed regional economy. Tourism Management, 48, 11-20.

https://doi.org/10.1016/j.tourman.2014.10.016

Kartono, J. L. (2012). Studi tentang konsep tatanan arsitektur Tionghoa di Surabaya yang dibangun sebelum tahun 1945. DIMENSI (Jurnal Teknik Arsitektur), 39(2), 101-110. https://doi.org/10.9744/dimensi.39.2.101-110

Lawton, L. J., \& Weaver, D. B. (2009). Travel agency threats and opportunities: The perspective of successful owners. International Journal of Hospitality and Tourism Administration, 10(1), 68-92. https:// doi.org/10.1080/15256480802557283

Louangrath, P. (2014). Sample size determination for non-finite population. International Conference on Discrete Mathematics and Applied Sciences, at Bangkok, Thailand, (May), 1-24. https:// doi.org/10.13140/2.1.4785.7286

Louangrath, P., \& Rewtrakunphaiboon, W. (2013). Determination of a minimum sample size for film-induced tourism research. Silpakorn 70th Anniversary International Conference 2013, at Bangkok, Thailand, (July), 1-15. https:// doi.org/10.13140/2.1.2090.5605

Lusticky, M., \& Kincl, T. (2012). Tourism destination benchmarking: Evaluation and selection of the benchmarking partners. Journal of Competitiveness, 4(1), 99-116. https:// doi.org/10.7441/joc.2012.01.08

Mariyono, J. (2017). Determinants of demand for foreign tourism in Indonesia. Jurnal Ekonomi Pembangunan: Kajian Masalah Ekonomi dan Pembangunan, 18(1), 82. https://doi.org/10.23917/jep.v18i1.2042

Oktavio, A. (2017). Pengaruh business process reengineering terhadap business process performance pada hotel budget di Surabaya. Jurnal Ilmiah Manajemen dan Akuntansi: Ekonomika'45, 4(2), 163-175. Retrieved from http://dspace.uc.ac.id/handle/123456789/1127

Pemerintah Kota Surabaya. (2016). Peraturan Daerah Kota Surabaya No. 10 Tahun 2016 Tentang Rencana Pembangunan Jangka Menengah Daerah Kota Surabaya Tahun 2016-2021. Surabaya. Retrieved from https://jdih.surabaya.go.id/pdfdoc/perda_757.pdf

Prasetya, D. E., \& Wibisono, A. B. (2015). Buku etnofotografi “Cino Pecinan Suroboyo." Createvitas, 4(2), 261-274.

Priyadi, M. P. (2000). Perencanaan stratejik. Ekuitas, 4(2), 61-77.

Sekretariat Kabinet RI. (2017). Laporan 3 tahun pemerintahan Joko Widodo-Jusuf Kalla. Retrieved from http:/ / presidenri.go.id/wp-content/uploads/2017/10/FINAL-LAPORAN-3TAHUN-261017.pdf

surya.co.id. (2017, December 26). Kunjungan wisman ke Surabaya capai 9,6 Juta, ternyata 4 destinasi wisata ini favorit mereka. Surabaya. Retrieved from http:/ / surabaya.tribunnews.com/2017/12/26/2017-kunjungan-wisman-ke-surabayacapai-96juta-ternyata-4-destinasi-wisata-ini-favorit-mereka

Sutanto, D. H. (2016). Pentingnya promosi guna meningkatkan minat wisatawan wisata sejarah di Kota Lama Semarang. Jurnal Pariwisata Pesona, 1(1), 1-17. Retrieved from https:/ / doaj.org/article/259ae007f7c0498db91404a3002791e4 
Tranggono, D., Dwiridhotjahjono, J., Aryani, M. I., \& Rasyidah, R. (2015). Development formulation of crafts weaving batik ikat East Java: Strategic block and interconnection. Journal of Economics, Business \& Accountancy Ventura, 18(2), 167.

https://doi.org/10.14414/jebav.v18i2.445 